\title{
Processing waste from logging and woodworking enterprises into a non- conventional reclamation substrate using environmentally friendly technologies
}

\author{
Tatyana Galdina ${ }^{1,}$, , Anatoliy Kulakov ${ }^{2}$, and Valentin Rantsev-Kartinov ${ }^{2}$ \\ ${ }^{1}$ Department of Forest Plantations, Voronezh State University of Forestry and Technologies named \\ after G.F. Morozov, 8 Timiryazeva Street, 394087 Voronezh, Russia \\ ${ }^{2}$ Institute for Functional Economic Systems, 3/13 bldg. 1, Maroseyka Street, Moscow, Russia
}

\begin{abstract}
The article contains information about a newly developed technology for processing waste from logging and woodworking enterprises. The developers have proposed an environmentally friendly technology for processing organic waste into a product that has a strong land-reclamation effect and increases the natural potential of soils. The technology proposed by the authors is based on the unique technical capabilities of a developed machine - a highly efficient mill that grinds the waste into nano-sized fineness, and a highly efficient mixer that makes it possible to obtain homogeneous mixtures of various materials and different fineness. The unconventional substrate obtained from this method, due to the scientifically grounded composition and ratios of the composite components of organic waste, has effective land-reclamation properties that increase the soil potential, and restores the fertility of the humus horizon. The use of an unconventional land-reclamation substrate in nurseries increased the survival rate and growth rates of Scots pine (Pinus sylvestris) seedlings both in the open field and in greenhouses. Thus, the machine proposed by the authors in a single technological operation allows for the processing of waste from the logging and woodworking enterprises and ultimately to obtain a product that helps to increase the soil potential of degraded lands.
\end{abstract}

\section{Introduction}

The problem of waste disposal has been a global and urgent one for many centuries. But with the intensification of the globalization of human activity, the intensification of industry and other various segments of the economy, the issue of processing waste into a secondary product has become an issue of particular concern [1]. Recycling waste dramatically changes the economic and environmental aspects of our lives. It is the processing of waste into a secondary product which is available for consumption that corresponds to the main

\footnotetext{
${ }^{*}$ Corresponding author: invitro11@bk.ru
} 
environmental goals - restoring the environment, preserving natural resources, creating a healthy ecosystem, and reducing the volume of landfills.

The intensification of economic activity in the forest sector of the economy is currently causing a number of serious environmental problems [2]. Special types of anthropogenic impact include the pollution of the natural environment with the production and consumption of waste. The anthropogenic impact on agroecosystems, which results in soil degradation, is also an important issue [3-5] .

The degradation of agricultural land and forest resources is progressing ever-morerapidly, outstripping the natural processes of restoration, which increases the negative impact on the environment $[6,7]$.

At present, in order to increase the soil's potential, the lack of nutrients in the soil is compensated for by the introduction of mineral fertilizers [7,9]. However, this approach does not deal with the main tasks of preserving and restoring the fertility of degraded lands or increasing the natural potential of the soil horizon. The systematic application of mineral fertilizers ultimately has a downside and increases the negative impact on degraded soils [9$12]$.

Therefore, the question of finding the latest technical solutions that will address a number of pressing problems and reduce the negative impact on ecological ecosystems becomes relevant.

Currently, the problem of processing industrial waste from various types of industries is high on the agenda. In administrative forestry enterprises, which own huge reserves of forest products, huge amounts of wood waste accumulates in felling areas and on the territories of timber processing enterprises[13]. In the process of logging, only about $60 \%$ of the timber is used. The rest is waste, which is destroyed by incineration, which is harmful to the environment.

However, wood waste processing currently has a lot of areas for improvements: production of mulch, fuel briquettes, organic fertilizers, etc.

Organic fertilizer is prepared from wood waste, using a fairly simple composting process. The technology for the implementation of this production is based on the laying and equipment of trenches for the preparation of compost mass, as well as the time interval. It would be expedient to use such compost in order to improve the fertility of highly mineralized and loamy soils, which will improve the structure of soils [14].

\section{Methods and materials}

Having analyzed the difficult situation of waste disposal and recycling in the logging and woodworking industrial sector, a group of specialists developed and proposed the implementation of a technology for obtaining an unconventional meliorative substrate from organic waste [13-14].

Waste of organic nature was used as a material: organic solid waste, wood waste, woodworking waste, agricultural waste (straw, husk), deciduous litter, litterless manure, canyga . The influence of each component on soil productivity and productivity was studied earlier [15]. Initially, the composting technology was used, which is characterized by a duration in time and requires additional economic costs for rent, wages, and so on. Therefore, there is a need for a new technology that will reduce all costs when obtaining an unconventional meliorative substrate from organic waste.

This technology will allow solving a number of problems, reducing economic costs and increasing the environmental effect: to recycle waste from logging and woodworking enterprises without additional costs for renting areas, wages and produce products that provide an effective reclamation property, contribute to an increase in soil productivity, restoring the humus horizon of degraded lands, has a dosed fertilizing effect. 
The proposed technology is complex, as it is designed to obtain new materials from various production and consumption wastes. This technology is based on the unique technical possibilities of "Universal Multipurpose Modules" (Fig. 1), a highly efficient mill, which is capable of grinding any material, regardless of it's hardness and plasticity, up to nano-size fineness, and is a highly efficient mixer that allows you to obtain homogeneous mixtures of different materials and of different fineness.

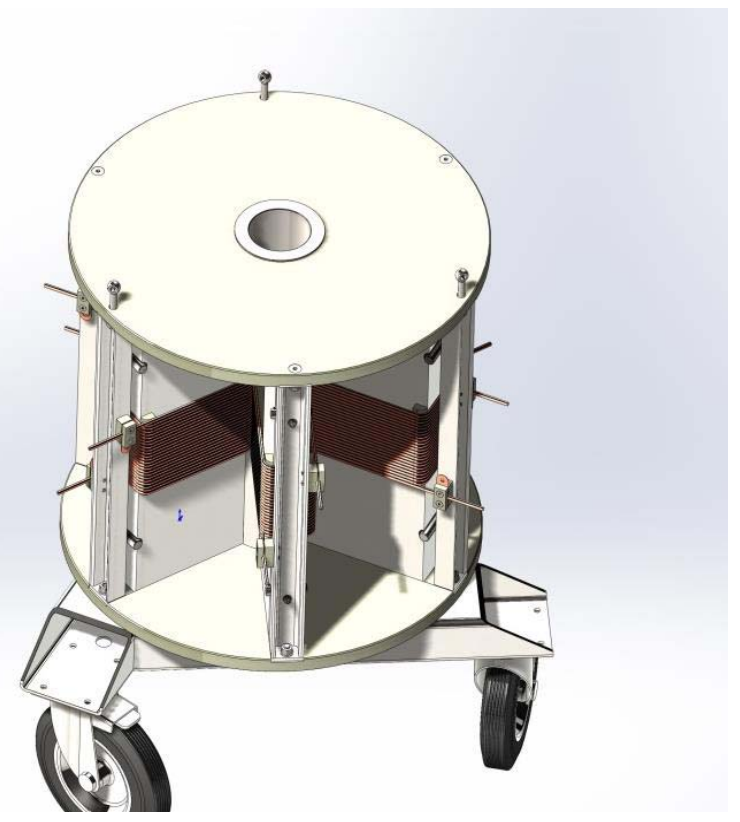

Fig. 1. UMM unit assembly-02.

The proposed technology allows you to recycle any waste of logging and woodworking: sawdust, shavings, wood dust, wood chips, slabs, cuttings, small-sized wood, "stale" waste, which, as mentioned above, has accumulated in abundance.

The key link in solving the problems of processing wood waste into an unconventional reclamation substrate is a highly efficient technology based on the use of various modifications of "Universal Multipurpose Modules" [1,8] as the main building blocks in ecological technological chains (Fig. 2) when setting them up for any planned capacity and output of the final product of processing.

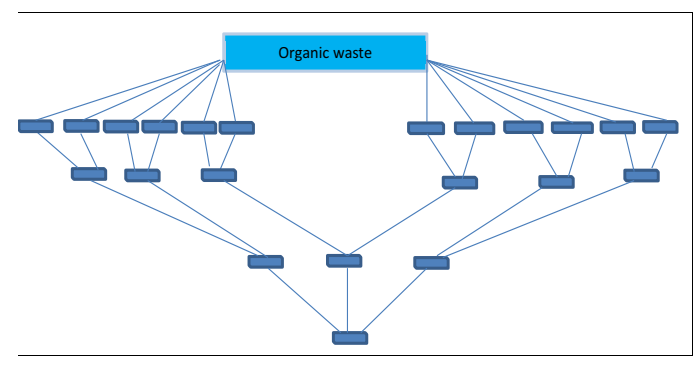

\section{UMM-RANKAR-P}

Fig. 2. Scheme of the technological chain of environmentally friendly technology for processing waste from logging and wood processing enterprises into an unconventional reclamation substrate. 
"Universal multipurpose modules" inherently relate to the field of intense grinding and mixing of bulk / liquid media.

The modules are based on highly efficient:

- disintegrators (mills that grind various processed materials, regardless of their hardness and viscosity, to nano-sizes);

- mixers (allowing to obtain homogeneous mixtures of various substances and high-quality suspensions of almost immiscible liquids, such as water, oil);

- activators of physical / chemical processes (allowing to increase the speed of the corresponding reactions in the used technologies by tens of thousands of times).

The high efficiency of the use of "Universal Multipurpose Modules" in ecological technological chains is due to the fact that all these processes take place in their working zones simultaneously, as well as the many physical and chemical processes leading to them. So, their versatility and high efficiency is due to:

a) the multitude and activity of the processes occurring in their working zones:

$\checkmark$ crushing by means of a "constrained blow";

$\checkmark$ electromagnetic erosion;

$\checkmark$ plasma exposure;

$\checkmark$ ultrasound (when processing in a liquid medium);

b) the high energy density of magnetic induction in its working area (at B $\sim 10^{4} \mathrm{Gs}, \mathrm{W} \sim 0.4$ $\mathrm{J} / \mathrm{cm}^{3}=410^{5} \mathrm{~J} / \mathrm{m}^{3}$ ), hundreds of times higher than the energy density in the working areas of other similar devices;

c) almost one hundred percent efficiency;

d) low material consumption.

\section{Results and discussion.}

The basis for the very high efficiency of the proposed environmentally friendly technology is the development and use of quantum plasma condensate, which allows you to recycle production waste without harmful emissions into the atmosphere.

Environmentally friendly technology is a chain of UMMs, which are three-phase electromagnetic motors with distributed rotors in the form of needles that form an active ferromagnetic vortex layer in their working zones, the original substance, when passing through them, is processed (crushed, mixed, activated, etc.). Their versatility is manifested in the fact that they can be highly efficiently used in various branches of industrial production.

Thus, to obtain an unconventional reclamation substrate, which includes: organic solid waste $(10 \%)$, wood waste $(35 \%)$, woodworking waste $(20)$, agricultural waste (straw, husk) $(10 \%)$, deciduous litter (5\%), litterless manure (10-20\%), canyga (10-20\%), we offer a developed environmentally friendly technology, based on UMM, which allows you to obtain a ready-to-use product - an unconventional reclamation substrate in one technological operation.

The main and most important link in the technological solution for the production of an unconventional substrate is a scientifically grounded ratio of raw materials, which makes it possible to obtain a competitive product with reclamation properties, which functions as an organic fertilizer.

An unconventional substrate, due to the scientifically grounded composition and ratios of composite components of organic waste, has effective properties as an ameliorant, as well as as an organic fertilizer. Decomposing in the ground, an unconventional substrate develops in 
the humus layer of the soil, which significantly increases its fertility and the content of nutrients in it. In addition, the introduction of an unconventional substrate contributes to the regulation of biological processes in the soil and triggers the activity of soil microorganisms, which significantly increases the soil potential of degraded lands and the survival rate, growth of seedlings (Table 1, Fig. 3) and the productivity of forest crops.

Table 1. Average height of 1-year-old Scots pine (Pinus sylvestris L.) seedlings, with preliminary application of fertilizers during soil preparation (2018).

\begin{tabular}{|c|c|c|c|c|}
\hline \multirow[b]{2}{*}{ No. } & \multirow[b]{2}{*}{ Option name } & \multicolumn{2}{|c|}{ Scots pine seedlings height, $\mathrm{cm}$} & \multirow{2}{*}{$\begin{array}{c}\text { Percentage } \\
\text { of the } \\
\text { control } \\
\text { group } \\
\end{array}$} \\
\hline & & $\mathbf{M} \pm \mathbf{m}$ & $\mathbf{T}_{\text {actual. }}$ & \\
\hline 1 & Control (no application) & $2.4 \pm 0.10$ & - & 100.0 \\
\hline 2 & $\begin{array}{ll}\text { Unconventional substrate } \\
(3000)\end{array}$ & $4.2 \pm 0.14$ & 10.3 & 171.9 \\
\hline 3 & $\begin{array}{lll}\begin{array}{l}\text { Organic } \\
(16: 16: 16)\end{array} & \text { NPK } & \text { fertilizers } \\
\end{array}$ & $2.5 \pm 0.07$ & 0.3 & 101.8 \\
\hline
\end{tabular}

Note hereinafter: $1-*-t_{\text {actual. }} \geq \mathrm{t}_{\text {table. }}$ (the difference in comparison with the control group is significant at $\left.\mathrm{HCP}_{05}\right) .2-t_{\text {table. }}=1.98$.

Our experiments on the practical application of the resulting product on environmentally friendly technology allow us to confidently recommend our developments to nurseries and greenhouse complexes.

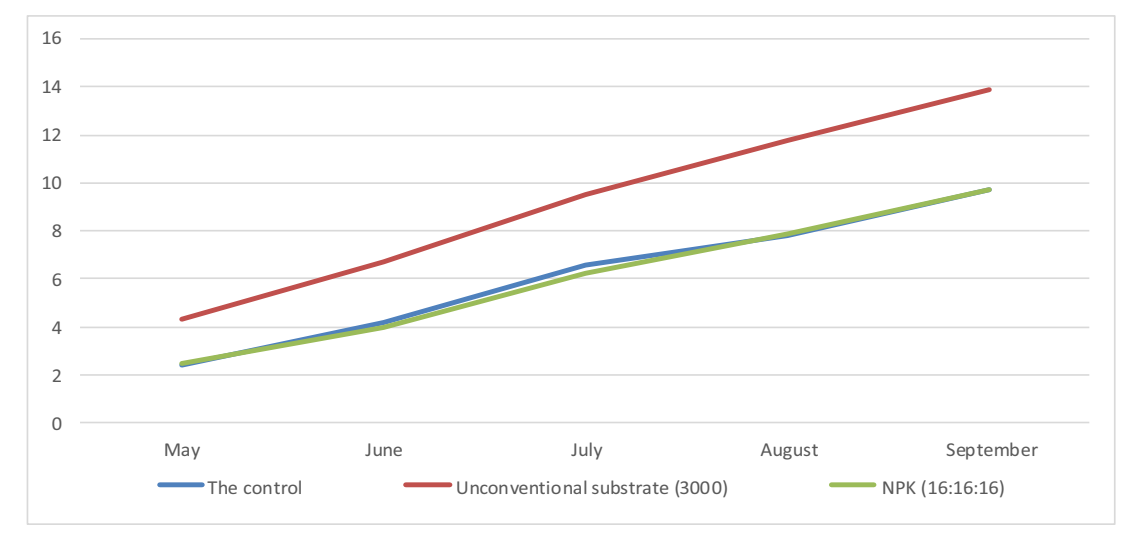

Fig. 3. Dynamics of growth in height of 2-year-old Scots pine seedlings (2019) in areas with preliminary application of fertilizers, an unconventional substrate during soil preparation

The use of an unconventional ameliorative substrate in a nursery by preliminary application during soil cultivation with a rate of 3 tons per 1 ha significantly increases the growth of Scots pine seedlings in the first year (71.9\% higher than the control group) (Table 1). The effect of this application of the ameliorative substrate persists in the second year of growing Scots pine seedlings, as evidenced by the growth dynamics (Fig. 3). Throughout the growing season, there is an intensive growth of seedlings in the area with the addition of the unconventional ameliorative substrate, which exceeds the growth of seedlings without the application of fertilizers and substrate, as well as with the application of mineral complex fertilizers (Fig. 3).

Another area of using non-traditional reclamation substrate is the technology developed by us for growing seedlings with a closed root system in containers. At the same time, an unconventional substrate can be used as an additive to lowland peat. The introduction of an 
unconventional substrate into the composition of lowland peat made it possible to significantly improve the properties of the substrate and obtain a higher quality planting material with closed roots (Fig. 4, 5, Table 2).

In the greenhouse complex, experiments were carried out on the addition of an unconventional meliorative substrate to peat in a 1:2 ratio (substrate: peat) to fill the cassettes. Scots pine seeds were sown into cassettes.

The effectiveness of the use of the unconventional ameliorative substrate when growing seedlings in cassettes indicates an increase in the yield and quality of planting material for 1 year (Fig. 4, 5).

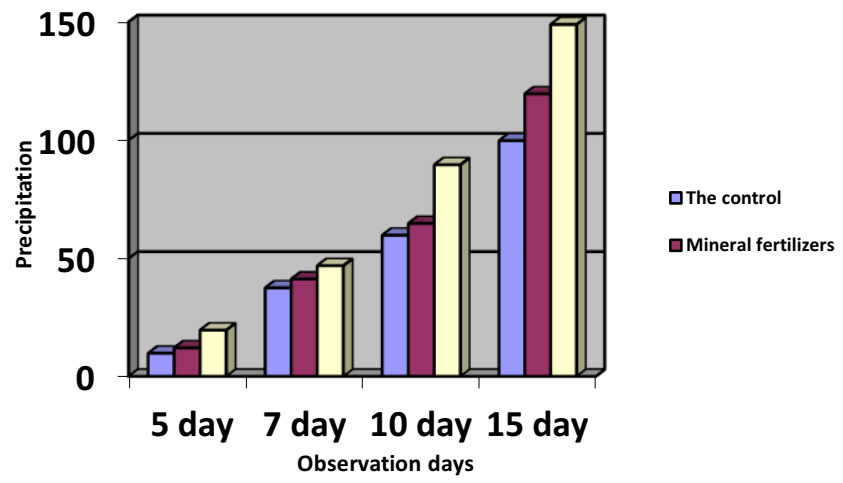

Fig. 4. Average dynamics of Scots pine seed germination in cassettes

Table 2. Influence of introducing an unconventional ameliorative substrate into lowland peat on biometric parameters of Scots pine grown in containers (2019)

\begin{tabular}{|c|c|c|c|c|c|c|}
\hline \multirow{2}{*}{$\begin{array}{c}\text { HC } \\
\text { share, } \%\end{array}$} & \multirow{2}{*}{$\begin{array}{c}\text { Stem } \\
\text { height, } \\
\text { cm }\end{array}$} & \multirow{2}{*}{$\begin{array}{c}\text { Root neck } \\
\text { diameter, }\end{array}$} & \multirow{2}{*}{$\begin{array}{c}\text { Root system } \\
\text { mm }\end{array}$} & length, cm & \multicolumn{3}{|c|}{ Weight of 100 plants, $\mathbf{g}$} \\
\cline { 5 - 7 } & 5.9 & 1.24 & 14.1 & 10.2 & 2.9 & 5.0 \\
\hline 0 & 6.9 & 1.66 & 22.7 & 15.0 & 6.7 & 17.5 \\
\hline 20 & 6.1 & 1.37 & 9.1 & 17.1 & 7.1 & 9.0 \\
\hline 30 & 11.4 & 1.81 & 27.8 & 18.1 & 9.0 & 10.5 \\
\hline 50 & 8.6 & 1.49 & 26.8 & 13.5 & 4.1 & 10.2 \\
\hline 70 & 5.1 & 1.03 & 10.9 & 9.5 & 2.5 & 3.8 \\
\hline 100 & & & & & & \\
\hline
\end{tabular}

A mixture of an unconventional ameliorative substrate and lowland peat in a 1:2 ratio in its properties is close to a substrate based on high-moor peat, the germination and survival rate of seedlings on this substrate is significantly higher than when using a substrate based on lowland peat and a pure unconventional reclamation substrate (Table 2 ).

It is noted that the effect of using the unconventional substrate is manifested when sowing in cassettes. The number of germinating seedling of Scots pine in cassettes increased by $20 \%$ from the control group on the fifth and seventh days of observation. In general, the germination capacity increased by $40 \%$ compared to the control group and by $22 \%$ with the introduction of mineral fertilizer (Fig. 5).

When checking the agrochemical composition of soils a year after the introduction of the unconventional substrate, the high content of organic matter $(9.2 \%$ at a depth of the arable 
layer of $24 \mathrm{~cm}$ ) and microelements, necessary for good nutrition and plant development, could be noted.

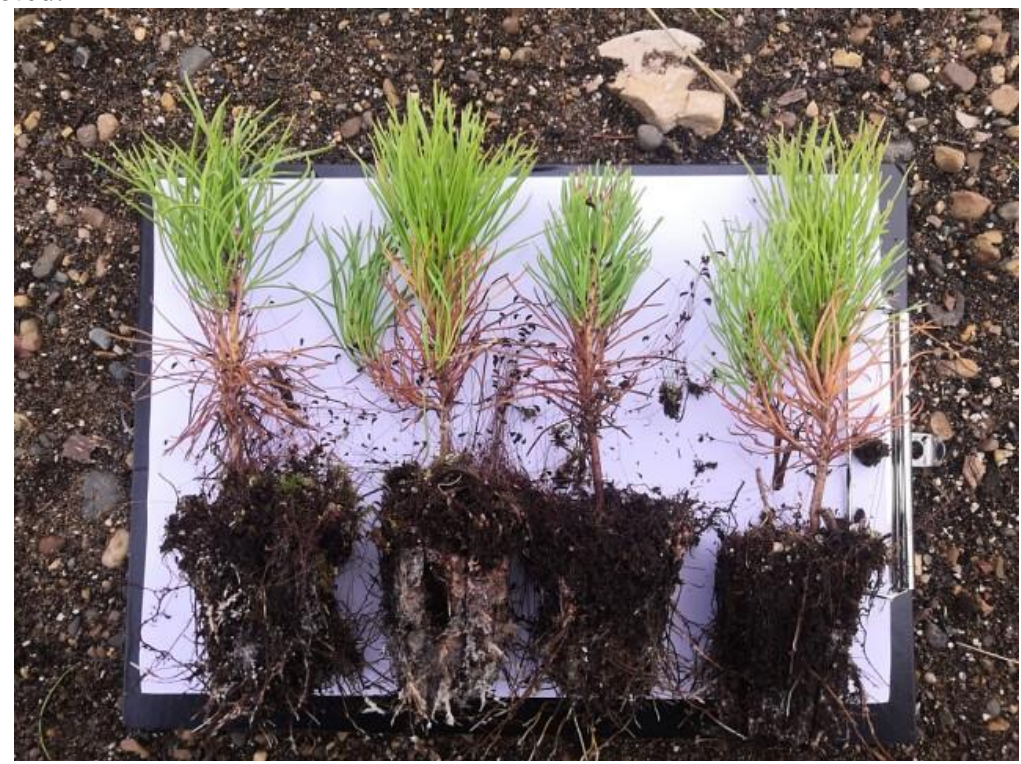

Fig. 5. Annual seedlings of Scots pine, grown in closed ground with the addition of prepared nontraditional ameliorative substrate in cassettes (2019)

The most important physical property of soil is porosity, which determines a number of very important qualities such as moisture capacity, water permeability, air permeability, speed and height of rise of the lower layers of the soil to the upper ones. So, when introducing an unconventional ameliorative substrate during plowing, it increases the porosity at a depth of $24 \mathrm{~cm}$ by $40 \%$ of the control (without application). After a year, the porosity decreases, but is $27 \%$ higher than the control.

\section{Conclusions}

The main direction of using waste from logging and woodworking enterprises in forestry is the production of unconventional fertilizers and substrates, the use of which makes it possible to increase soil fertility, intensifies the growth of woody and shrub plants in forest nurseries, greenhouses and forest plantations. But for an effective and wide range of applications of non-traditional substrates based on organic waste, it is necessary to introduce the latest environmentally friendly technologies that reduce economic costs and negative impact on ecological ecosystems.

The use of technology from the chain of "Universal Multipurpose Modules", which gives grinding to nano-size fineness and mixing various materials and different fineness of grinding to a homogeneous mixture, allows to obtain a ready-to-use product in one technological operation.

UMM technology will save on the creation of composting landfills, which have a negative impact on the environment.

The proposed technology will make it possible to recycle non-recyclable waste, thereby replacing the process of recycling waste from logging and woodworking enterprises by burning with more environmentally friendly methods, reducing the negative impact on ecosystems. 
With our developed technology, we solve several ecologically important tasks that allow us to increase the ecological safety of the environment in the forestry sector:

1. The raw material for the non-traditional substrate is organic waste from various fields of activity, including 55\% waste from logging and woodworking enterprises.

2. An unconventional substrate with a scientifically grounded recipe in practical application guarantees significantly higher aeration and faster drainage, creates a highly efficient environment, significantly changes and improves the fertile soil layer, thereby increasing the yield from 1 hectare by $50 \%$, has dosing properties of the consumption of trace elements plants. All this contributes to the preservation and restoration of soil fertility of degraded lands, increasing the natural potential of the soil horizon.

3. Application of the developed technology will make it possible to utilize organic production and consumption wastes formed from natural materials, to process them into a functional product (non-traditional reclamation substrate) with the above properties, without harmful emissions into the atmosphere.

\section{References}

1. A. Vurasco, E. Simonova, A. Minakova, Bulletin of the Perm National Research Polytechnic University. Applied ecology. Urban studies 2(30), 21-32 (2018) doi: 10.15593 / 2409-5125 / 2018.02.02

2. G. Antonov, O. Kondakova, A. Barchenkov, N. Sorokin, Forestry 1, $56-64$ (2018) doi: 10.7868 / S0024114818010059

3. T. Sullivan, D. Sullivan, Forest Ecology and Management 391, 207-220 (2017) doi.org/10.1016/j.foreco.2017.02.021

4. J. A. Franklin, C. E. Zipper, J. A. Burger, J. G. Skousen, D. F. Jacobs, New Forests 43, 905-924 (2012) doi: 10.1007 / s1 1056-012-9342-8

5. A. Sokolov, P. Alexey, V. Kharitonov, Bulletin of Higher Educational Institutions. Lesnoi Zhurnal (Forestry journal) 6, 42-55 (2016) 10.17238/issn0536-1036.2016.6.42.

6. N. Kovaleva, R. Sobachkin, Forestry, ISSN 0024-1148 1, 25-33 (2016)

7. I. Stepanenko, Izv. universities. Lesn. J. 4, 61-69 (2005)

8. N. Genikova, V. Kharitonov, A. Kryshen, Izv. universities. forest. J. 2, 35-50 (2020) doi: 10.37482 / 0536-1036-2020-2-35-50

9. N. Genikova, V. Kharitonov, Izv. universities. Lesn. J. 1, 18-28 (2018) doi: 10.17238 । issn0536-1036.2018.1.18

10. O. Shapchenkova, N. Kovaleva, V. Ivanov, R. Sobachkin, D. Sobachkin, A. Petrenko, Lesovedenie 1, 44-51 (2015)

11. N. Kovaleva, R. Sobachkin, Lesovedenie 1, 25-33 (2016)

12. A. Solodovnikov, N. Fedorets, A. Sokolov, Transactions of Karelian Research Centre of the Russian Academy of Sciences 5, 45-51 (2017) doi: 10.17076 / eb490

13. E. Romanov, D. Mukhortov, T. Nureeva, Glasnik Sumarskog fakulteta, 133-150 (2016) 10.2298 / GSF1613133R.

14. D. Mukhortov, E. Romanov, A. Mamaev, Forestry 3, 21-23 (2011)

15. T. Galdina, S. Samoshin, Achievements of modern natural science 11-1, 24-29 (2018) 